\title{
Incorporating the patient-centered approach into clinical practice helps improve quality of care in cases of hypertension: a retrospective cohort study
}

Nida Buawangpong ${ }^{1}$, Kanokporn Pinyopornpanish ${ }^{1 *}$ (D, Wichuda Jiraporncharoen ${ }^{1}$, Nisachol Dejkriengkraikul ${ }^{1}$, Pakorn Sagulkoo ${ }^{2}$, Chanapat Pateekhum ${ }^{1}$ and Chaisiri Angkurawaranon ${ }^{1}$

\begin{abstract}
Background: Treating hypertensive patients by integrating the patient-centered approach would influence the practice and outcome of treatment. Our purpose was to determine whether the implementation of a patientcentered approach in health care delivery can improve adhering to guidelines and the quality-of-care.

Methods: A retrospective study was conducted using secondary data from the electronic medical records of the patients treated in the two primary care outpatient settings at the Family Medicine (FM) and Social Security (SS) clinics. A key feature of the FM clinic is the incorporation of a patient-centered approach in its service delivery. Individual information regarding initial assessment and treatment at the follow-up visits was reviewed for 1 year. Comparison of adherence to treatment guidelines between the two primary care clinics was performed by using chi-square, Fisher's exact test or a t-test. To explore the difference in blood pressure and BP control between the two clinics, linear and logistic regression analysis respectively were performed with an adjustment for CV risk score in 2016 as a key confounder.
\end{abstract}

Results: The evidence included 100 records from each clinic, showed variation between the two primary care sites. The FM clinic had more complete records regarding family history of hypertension, assessment for secondary causes, prescription for lifestyle modification and appropriate adjustment of medication. Higher levels of blood pressure control were recorded in the FM clinic, specifically systolic pressure $2.92 \mathrm{mmHg}(p=0.073)$ and diastolic pressure $5.38 \mathrm{mmHg}(p<0.001)$ lower than those recorded in the SS clinic. There was a 2.96 times higher chance for BP goals to be achieved in patients in receipt of hypertensive care at the FM clinic $(p=0.004)$.

Conclusions: Adopting a patient-centered approach in service delivery could improve the quality of care for hypertension patients in primary care in Thailand.

Keywords: Primary health care, Family medicine, Patient-centered medicine, Hypertension, Guidelines, Clinical practice

\footnotetext{
* Correspondence: kpinyopo@gmail.com

${ }^{1}$ Department of Family Medicine, Faculty of Medicine, Chiang Mai University,

110 Inthawarorot Rd., Sriphum, Muang, Chiang Mai 50200, Thailand

Full list of author information is available at the end of the article
}

\section{$\triangle B M C$}

(c) The Author(s). 2020 Open Access This article is licensed under a Creative Commons Attribution 4.0 International License, which permits use, sharing, adaptation, distribution and reproduction in any medium or format, as long as you give appropriate credit to the original author(s) and the source, provide a link to the Creative Commons licence, and indicate if changes were made. The images or other third party material in this article are included in the article's Creative Commons licence, unless indicated otherwise in a credit line to the material. If material is not included in the article's Creative Commons licence and your intended use is not permitted by statutory regulation or exceeds the permitted use, you will need to obtain permission directly from the copyright holder. To view a copy of this licence, visit http://creativecommons.org/licenses/by/4.0/ The Creative Commons Public Domain Dedication waiver (http://creativecommons.org/publicdomain/zero/1.0/) applies to the data made available in this article, unless otherwise stated in a credit line to the data. 


\section{Background}

Hypertension is one of the leading causes of mortality worldwide and the number of patients is increasing [1, 2]. Uncontrolled blood pressure (BP) leads to the serious complications such as cardiovascular diseases [3]. It has been found that BP in $35.8 \%$ of patients in Thailand cannot be controlled [4].

Treating hypertensive patients by complying with standard treatment guidelines would create more BP controlled [5-8], and consequently reduce the morbidity and mortality $[9,10]$. However, there might be some barriers preventing physicians from adhering strictly to treatment guidelines, including the attitude and practice of the physician, complexity of recommendations, and the actual setting (timing and availability of facilities and tools) [11]. Furthermore, in order to achieve the treatment goals, it is not only how the physicians treat, but also how the patient gets involved in the management of their own health care process [12].

Many hypertension treatment guidelines advocate a patient-centered approach to be integrated in all aspects of service care $[13,14]$. The integration of a patientcentered approach into service delivery can be formalized through the concept of a patient-centered medicine (PCM) approach. The concept of PCM includes six main components [15]: exploring both the disease (biomedical aspect) and the illness experience (psychosocial aspect); understanding the whole person (context); finding common ground (for treatment); incorporating prevention and health promotion; enhancing the patient-doctor relationship; and being realistic. These six components of care promote collaboration between the doctor and patient by concerning the patient's context, including socioeconomic status, in treatment plans and focusing on continuity of care [16-19].

Thailand has incorporated the concept of PCM into the Thai hypertension treatment guidelines since 2015. It was recommended briefly in one paragraph that physicians should concern themselves with forming individual treatment plans for the patients [10]. The formal concept of PCM has only been introduced and adopted as part of the competency in Family Medicine since the start of the training program in Thailand about 15 years ago [20].

In order to assess the potential benefits of integrating PCM in delivering healthcare to hypertensive patients, a clinical audit of medical records was carried out in two primary care clinics. The clinics were: 1 ) the family practice clinic run by the Department of Family Medicine (FM clinic) and 2) the general practice clinic for patients under the social security scheme (SS clinic). Both clinics are part of Maharaj Nakorn Chiang Mai Hospital, they have access to the same physical resources from the hospital, such as readiness of facilities and tools, capability of further assessment or medical record system. The differences between the two clinics are described in the Methods section.

The aim of this review was to explore whether adherence to hypertension treatment guidelines differs between these two different service settings, effect on ability to do PCM, and to explore whether the differences are associated with better control of hypertension.

\section{Methods \\ Study design}

This is a retrospective review of electronic medical records of patients who received hypertension treatment in FM clinic and SS clinic in Maharaj Nakorn Chiang Mai Hospital.

\section{Setting}

FM clinic is a teaching and service clinic for medical students and family medicine residents. The service in this clinic is generally provided by Family Medicine residents and staff who are trained in the PCM approach. The number of patients per day is restricted. An appointment can be made to see the same physician for continuity of care.

The SS clinic is a clinic to serve patients who use the social security scheme. The service being provided by a rotation of the residents and staff who are trained in a variety of specialisms. Consequently, there are variations in practice between the physicians and continuity of care by the same physician is nearly impossible. Supplementary Table 1, Additional file 1 shows the details of the differences between these two clinics.

\section{Data collection}

The sample size calculation was conducted based on the prior statistical evidence in these two clinics. The hypertension control rate of FM clinic and SS clinic were 65 and $45 \%$, respectively. We used the two independent proportion formula. To reach a power of $80 \%$ and alpha value of 0.05 , the estimated size sample was 96 people per unit of service. We then decided to take 100 samples from each clinic.

The first 100 hypertensive patients from each clinic that met the inclusion criteria were included in the review. The inclusion criteria were those who had a record of any visit in October 2016 and had records of further visits in a 1 year follow up period in September 2017. To avoid cross contamination, any records of the patients who had a consultation with a family medicine physician in the SS clinic were excluded. As about 5\% of the services in SS clinic provided by family physicians which would impact the interpretation. The first 20 records of the same patients from each clinic were reviewed independently by two researchers (NB and PS). The reviewers compared their assessment and any 
disagreement was resolved through discussion and consensus. The next 160 records (80 for each reviewer) were randomly assigned and reviewed by either one of the two researchers.

\section{Adherence to treatment guidelines}

The Thai guidelines for treatment of Hypertension 2015 follows the 2013 Practice guidelines for the management of arterial hypertension by the European Society of Hypertension and the European Society of Cardiology and The Sixth Report of the Joint National Committee on Prevention, Detection, Evaluation and Treatment of High Blood Pressure [10]. The researchers developed a case record form by referring to these treatment guidelines which were broken down into four broad sections:

1) Initial assessment

2) Continuous monitoring and assessment for target organ damage (TOD)

3) Prescription for lifestyle modification

4) Prescription of medication and dose adjustment

For section 1, detailed accurate initial assessment at diagnosis, evaluation of secondary hypertension, and family history assessment. For section 2, continuous monitoring and assessment for TOD records were assessed to see whether they had such investigations. For lifestyle modifications in section 3, the medical records were assessed for whether there was any documentation of lifestyle modifications. For prescription of medication in section 4, records were assessed whether the physician had adhered to the recommended dosage and class of hypertensive medication as well as whether the physician adjusted the dose of the medication when the target blood pressure was not achieved. The definition and assessment period for each topic can be found in Supplementary Table 2, Additional file 2.

\section{Blood pressure control}

The mean BP over the year, excluding the first BP in October 2016 (as the first BP was included in cardiovascular (CV) risk assessment and treated as a confounder), was used as an outcome and also used to classify whether the control of BP was achieved. BP goals were $140 / 90 \mathrm{mmHg}$ for general patients and $130 / 80 \mathrm{mmHg}$ for chronic kidney disease patients with proteinuria, diabetes patients aged 50 years or less or with albuminuria.

\section{Statistical analysis}

Comparison of adherence to treatment guidelines between the two primary care clinics was performed by using chi-square, Fisher's exact test or a t-test. To explore the difference in blood pressure and BP control between the two clinics, linear and logistic regression analysis respectively were performed with an adjustment for CV risk score in 2016 as a key confounder. A CV risk calculation was done using a Thai CV Risk Score application which estimates the 10-year risk of developing a major cardiovascular event based on the patients age, gender, smoking behavior, presence of diabetes and their last measurement of blood pressure, total cholesterol, low-density lipoprotein cholesterol (LDL-C) and highdensity lipoprotein cholesterol (HDL-C) in 2016. The software used for analysis was STATA (version 15.1).

\section{Results}

Age, comorbidities, type of antihypertensive drug, and the $\mathrm{CV}$ risk between the patients attending the two clinics were statistically significant differences (described in Table 1). Patients attending the FM clinic were older than those attending the SS clinic (mean age 61.68 vs $52.14, p<0.001)$ with a higher average percentage of 10 -year CV risk $(12.8 \pm 7.75$ vs $6.90 \pm 5.28, p<0.001)$.

\section{Initial assessment}

Documentation of the initial assessment in the medical records of patients treated at the FM clinic had more complete history taking records for both family history (26\% vs $2 \%, p<0.001)$ and secondary causes of hypertension than those in the SS clinic $(76 \%$ vs $60 \%, p=$ 0.015). Only about $4 \%$ of patients had documentation pertaining to the physical examination for evidence of secondary hypertension in both clinics (Table 2).

\section{Continuous monitoring and assessment for TOD}

The evidence of history taking of hypertension related symptoms or TOD, and risk factors was more complete in the FM clinic. Both clinics monitored blood pressure at a high rate. However, calculation of body mass index was documented in only $24 \%$ of patients attending the FM clinic and in only $2 \%$ of patients attending the SS clinic $(p<0.001)$. Most patients $(>90 \%)$ had their glucose, lipid profiles and kidney function monitored in both clinics (Table 3).

\section{Prescription for lifestyle modification}

Prescription for lifestyle modification was not commonly recorded. Details are described in Table 4. However, it is noted that it was more commonly recorded in the FM clinic. Advice given on exercise (51\% FM clinic vs $17 \%$ SS clinic, $p<0.001)$ and dietary approach (46\% FM clinic vs $27 \%$ SS clinic, $\mathrm{p}=0.005$ ) was of statistically significantly higher incidence at the FM clinic.

\section{Prescription of medication and dose adjustment}

In case of the appropriateness of choice of type and dosage of anti-hypertensive drug treatment, the majority (over 90\% of patients) received appropriate initial 
Table 1 Characteristics of the patients in the FM and SS clinics

\begin{tabular}{|c|c|c|c|}
\hline Characteristics & FM clinic $N=100$ & SS clinic $N=100$ & $P$-value \\
\hline Female gender, $\mathrm{n}$ & 55 & 65 & 0.149 \\
\hline Age (year), mean (SD) & $61.68(6.44)$ & $52.14(7.03)$ & $<0.001^{\mathrm{a}}$ \\
\hline BMI $\left(\mathrm{kg} / \mathrm{m}^{2}\right)$, mean $(\mathrm{SD})$ & $26.10(4.12)$ & $26.29(3.77)$ & $0.738^{\mathrm{a}}$ \\
\hline Education level ${ }^{c}, \mathrm{n}(\%)$ & & & 0.120 \\
\hline - Primary school or lower & 9/30 (30.00) & $27 / 58(46.55)$ & \\
\hline - High school/ Vocational school & $11 / 30(36.67)$ & $22 / 58(37.93)$ & \\
\hline - Bachelor's degree or higher & 10/30 (33.33) & 9/58 (15.52) & \\
\hline Occupation with regular salary ${ }^{c}, \mathrm{n}(\%)$ & $41 / 69(59.42)$ & $16 / 65(24.62)$ & $<0.001$ \\
\hline \multicolumn{4}{|l|}{ Comorbidities } \\
\hline - Diabetic mellitus type $\|, \mathrm{n}$ & 34 & 39 & 0.463 \\
\hline - Dyslipidemia, n & 86 & 55 & $<0.001$ \\
\hline - Chronic kidney disease, $\mathrm{n}$ & 8 & 4 & 0.234 \\
\hline - Cerebrovascular disease, $\mathrm{n}$ & 9 & 0 & $0.003^{b}$ \\
\hline - Cardiovascular disease, n & 6 & 0 & $0.029^{\mathrm{b}}$ \\
\hline Use of anti-hypertensive drugs for 1 year & 92 & 99 & $0.035^{\mathrm{b}}$ \\
\hline \multicolumn{4}{|l|}{ Current anti-hypertensive drugs } \\
\hline - Calcium channel blockers, n & 62 & 66 & 0.556 \\
\hline - Beta blockers, n & 6 & 24 & $<0.001$ \\
\hline - ACE inhibitors, $n$ & 9 & 32 & $<0.001$ \\
\hline - Angiotensin II receptor blockers, n & 47 & 25 & 0.001 \\
\hline - Mineralocorticoid receptor antagonists, $n$ & 1 & 0 & $1.000^{\mathrm{b}}$ \\
\hline - Diuretics, n & 7 & 12 & 0.228 \\
\hline Active alcohol drinker ${ }^{c}, \mathrm{n}(\%)$ & $21 / 87(24.0)$ & $22 / 100(22.0)$ & 0.729 \\
\hline Current smoker ${ }^{c}, \mathrm{n}(\%)$ & 4/86 (4.65) & 2/100 (2.00) & $0.417^{b}$ \\
\hline Percentage CV risk calculation, mean (SD) & $12.80(7.75)$ & $6.90(5.28)$ & $<0.001^{a}$ \\
\hline \multicolumn{4}{|l|}{ Baseline BP (mmHg), mean (SD) } \\
\hline - Systolic BP & $134.96(13.8)$ & $137.36(14.5)$ & $0.232^{\mathrm{a}}$ \\
\hline - Diastolic BP & $77.76(10.52)$ & $82.03(9.68)$ & $0.003^{\mathrm{a}}$ \\
\hline \multicolumn{4}{|l|}{ Mean BP in 1 year (mmHg), mean (SD) } \\
\hline - Systolic BP & $132.71(10.7)$ & $134.21(10.1)$ & $0.308^{\mathrm{a}}$ \\
\hline - Diastolic BP & $75.62(7.21)$ & $80.98(7.87)$ & $<0.001^{\mathrm{a}}$ \\
\hline \multicolumn{4}{|l|}{ Mean BP excluding baseline (mmHg), mean (SD) } \\
\hline - Systolic BP & $131.99(11.2)$ & $132.90(10.2)$ & $0.548^{\mathrm{a}}$ \\
\hline - Diastolic BP & $74.98(7.54)$ & $80.47(8.64)$ & $<0.001^{a}$ \\
\hline
\end{tabular}

$B M I$ body mass index, $B P$ blood pressure

${ }^{a}$ t-test

${ }^{b}$ Fisher's exact test

c Evaluated among those with data in electronic records

Table 2 Evidence of initial assessment on history taking and physical examination

\begin{tabular}{|c|c|c|c|}
\hline Evidence of initial assessment on history taking and physical examination & FM clinic $N=100$ & SS clinic $N=100$ & $P$-value \\
\hline \multicolumn{4}{|l|}{ History taking } \\
\hline - Family history of hypertension, $\mathrm{n}$ & 26 & 2 & $<0.001^{\mathrm{a}}$ \\
\hline - Assessed for secondary hypertension, $\mathrm{n}$ & 76 & 60 & 0.015 \\
\hline \multicolumn{4}{|l|}{ Physical examination } \\
\hline - Evidence of secondary hypertension, $\mathrm{n}$ & 3 & 5 & 0.470 \\
\hline
\end{tabular}


Table 3 Evidence of continuous monitoring and assessment for target organ damage

\begin{tabular}{|c|c|c|c|}
\hline Topics & $\begin{array}{l}\text { FM clinic } \\
N=100\end{array}$ & $\begin{array}{l}\text { SS clinic } \\
N=100\end{array}$ & $\begin{array}{l}P \text { - } \\
\text { value }\end{array}$ \\
\hline \multicolumn{4}{|l|}{ History taking } \\
\hline - History of hypertension, $\mathrm{n}$ & 96 & 78 & $0.001^{\mathrm{a}}$ \\
\hline - Risk factors, n & 92 & 99 & $0.035^{\mathrm{a}}$ \\
\hline - Symptoms suggestive of TOD, & 85 & 65 & 0.001 \\
\hline \multicolumn{4}{|l|}{ Physical examination } \\
\hline - BP and PR measurement, $\mathrm{n}$ & 98 & 100 & $0.497^{\mathrm{a}}$ \\
\hline $\begin{array}{l}\text { - BMI calculation and WC } \\
\text { measurement, } \mathrm{n}\end{array}$ & 24 & 2 & 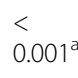 \\
\hline $\begin{array}{l}\text { - TOD and cardiovascular } \\
\text { disease, } \mathrm{n}\end{array}$ & 85 & 45 & $\begin{array}{l}< \\
0.001\end{array}$ \\
\hline \multicolumn{4}{|l|}{ Laboratory investigation } \\
\hline - Fasting plasma glucose, n & 93 & 99 & $0.065^{*}$ \\
\hline $\begin{array}{l}\text { - Serum TC, HDL-C, LDL-C, tri- } \\
\text { glyceride, } n\end{array}$ & 100 & 100 & N/A \\
\hline $\begin{array}{l}\text { - Serum electrolytes, Cr, GFR } \\
\text { calculation, } \mathrm{n}\end{array}$ & 94 & 99 & $0.118^{\mathrm{a}}$ \\
\hline - Hemoglobin or hematocrit, $\mathrm{n}$ & 43 & 43 & 1.000 \\
\hline - Urinalysis, n & 65 & 59 & 0.382 \\
\hline - Electrocardiography, n & 28 & 33 & 0.443 \\
\hline - $\mathrm{CV}$ risk assessment at OPD, $\mathrm{n}$ & 3 & 1 & $0.621^{\mathrm{a}}$ \\
\hline
\end{tabular}

treatment (Table 5). There was no evidence to suggest any difference in adherence to recommended guidelines for prescription of medication between the clinics. However, patients attending the FM clinic used more fixeddose combinations. When the BP was uncontrolled, $60.3 \%$ of patients in the FM clinic received adjustments to their mediation, comparison to $34.8 \%$ in the SS clinic $(\mathrm{p}=0.003)$.

\section{Blood pressure control}

Comparison of BP control between the clinics by adjusting for the calculated $\mathrm{CV}$ risk score, indicates there is some weak evidence to suggest that the average BP was lower among patients receiving care at the FM clinic. The average systolic blood pressure was $2.92 \mathrm{mmHg}$ lower among those attending the FM clinic $(95 \% \mathrm{CI}-$ 6.12 to $0.28, \mathrm{p}=0.073$ ) and the average diastolic blood pressure was $5.38 \mathrm{mmHg}$ lower (95\% CI -7.89 to -2.87 , $p<0.001)$ than those attending the SS clinic. After adjustment for CV risk score, patients attending the family medicine clinic were almost 3 times more likely to have a controlled average BP (OR 2.96, 95\% CI 1.41 to 6.22, $p=0.004)$.

\section{Discussion}

In general, at both clinics, there was good adherence to the clinical guidelines for initial assessment, continuous monitoring, assessment for TOD and correct initiation of medication. Documentation regarding prescription of lifestyle modification was low but was found more commonly among those attending the FM clinic. Patients were also more likely to receive adjustment to their medication if hypertensive control was not met at the FM clinic. Evidence suggested that the average BP was lower among patients receiving care at the FM clinic.

Analysis of history taking showed that history about family members experiencing hypertension was noted more by family physician. The PCM approach adopted by family physicians focuses on the patient context which includes a family-oriented approach. This issue might not be regularly assessed as it is not commonly used in making a plan for treatment. Shared behaviors among family members may affect patient's behaviors. The physician may use knowledge regarding the family's influence on behaviors in the counseling process. In addition, family support has been identified as one of the facilitators for patient's hypertension self-management [21]. A Family-oriented approach and enhancing health literacy to the family members could be beneficial in caring hypertension patients.

For physical examination and treatment planning, measurement of body mass index (BMI) and the assessment of 10-year CV risk were similarly low in both clinics. Both of these aspects are useful for raising of awareness in patients [22-24] and their physicians and enhance the efficacy of treatment [10, 25-28]. Technology could be used to help fill in the indices and CV risk

Table 4 Evidence of giving advice on lifestyle modification

\begin{tabular}{llll}
\hline Topics & FM clinic N=100 & SS clinic $N=100$ & $P$-value \\
\hline Weight reduction, $\mathrm{n}$ & 23 & 1 & $<0.001^{\mathrm{a}}$ \\
Appropriate exercise, $\mathrm{n}$ & 51 & 17 & $<0.001$ \\
Dietary approach, $\mathrm{n}$ & 46 & 27 & 0.005 \\
Limiting of alcohol intake for drinkers, n/No. of drinkers (\%) & $10 / 21(47.6)$ & $12 / 22(54.5)$ & 0.663 \\
Smoking cessation for smokers, n/No. of smokers (\%) & $1 / 4(25.0)$ & $1 / 2(50.0)$ & $1.000^{\mathrm{a}}$ \\
\hline
\end{tabular}

\footnotetext{
${ }^{a}$ Fisher's exact test
} 
Table 5 Evidence of appropriateness of prescription and adjustment of anti-hypertensive medication

\begin{tabular}{|c|c|c|c|}
\hline Topics & $\begin{array}{l}\text { FM clinic } N= \\
100\end{array}$ & $\begin{array}{l}\text { SS clinic } N= \\
100\end{array}$ & $\begin{array}{l}P \text { - } \\
\text { value }\end{array}$ \\
\hline Ever used an anti-hypertensive drug during the last year, $n$ & 92 & 99 & $0.035^{\mathrm{a}}$ \\
\hline Starting with appropriate dosage of medication, $\mathrm{n}(\%)$ & 91/92 (98.9) & $99 / 99(100)$ & $0.482^{\mathrm{a}}$ \\
\hline Use of an appropriate class at the start, $\mathrm{n}(\%)$ & 88/92 (95.6) & 94/99 (94.9) & $1.000^{\mathrm{a}}$ \\
\hline Choice of the most appropriate medication for the specific conditions, n (\%) & 79/92 (85.9) & $88 / 99(88.9)$ & 0.663 \\
\hline Never used ACEls together with ARBs, n/No. of patients using more than one type of medication (\%) & $34 / 34(100)$ & 47/48 (97.9) & $1.000^{\mathrm{a}}$ \\
\hline Prescription of fixed-dose combinations, n/ No. of patients using more than one type of medication (\%) & 12/34 (35.3) & $3 / 48(6.25)$ & 0.001 \\
\hline $\begin{array}{l}\text { Adjustment of dosage of medication when blood pressure goal not achieved, n/No. of patients who had ever } \\
\text { had uncontrolled BP (\%) }\end{array}$ & $38 / 63(60.3)$ & 24/69 (34.8) & 0.003 \\
\hline
\end{tabular}

results prior to the examination. The results show that the number of patients screened for smoking and alcohol drinking was higher in the SS clinic as it routinely done by the nurses before seeing the physician following the standard record form. This suggests that task shifting could be shared among the different types of care providers to help improve adherence to clinical guidelines [29]. Moreover, using assistive tools such as a welldeveloped order set could help improve compliance for assessment and management [30].

Appropriate adjustment of the dose and discussing on changing risky behaviors are practiced more frequently in the FM clinic, may be due to the longer consultation time available which allows for PCM and the finding of workable ways forward and common ground [31]. The goal is initially set together, promoting the development of trust and a good relationship. The continuity of care with the same physician would give a higher chance of agreement on dosage modification and overall management with consent [32, 33].

The evidence concerning the measurement of the integration of PCM in practice using the routine data records is scarce [34]. However, this is concurrent with the results from prior studies that adherence to guideline is associated with better BP control [5-7]. The implementation of PCM also shows a correlation with better quality of care and patient outcomes. This is supported by the results from other countries that person-centered care in hospitalized patients can improve health outcomes [35, 36].

These findings suggest that adopting a more PCM approach in the delivery of primary care services may help improve hypertensive care in Thailand through increased adherence to standard guidelines which would subsequently improve control of BP. Any method to enhance the PCM practice should be useful. This should include concerning more about family context, collaborating with the patient in making a treatment plan and supportive service system.

\section{Strengths and limitations}

The strength of this study was the use of the same electronic medical record system which standardized many aspects of the data. This reflects real world practice as well as being able to control importation systems and contextual factors associated with hypertensive control. However, there were some limitations. Firstly, data was derived from routine records, which might underestimate the adherence to guidelines if these practices are not documented. The necessitated faster clinical pace in the SS clinic could lead to poorer documentation. There is a need for recognition by all stakeholders that every record is important, especially in the case of continuity of treatment. All information related to disease assessment and treatment should recorded even if it only consists of a short phrase. Due to time pressures in the SS clinic the use of administrators to complete records would ease the workload. Secondly, further adjustments for SES were not possible as it's not routinely recorded in electronic records database and the interpretation of results could be limited by the decreased sample size. Due to the small sample size and from using one clinic in each arm in a single setting, the results may not be generalizable. Further research using multiple settings would be useful. Moreover, PCM should have already been tailored to each individual socioeconomic conditions. Finally, the study was conducted under the hypothesis that PCM is integrated in the practice and services. The performance pertaining to PCM was not directly measured as our aim was not to assess the perceptions or experiences about PCM practice as conducted in most studies [34]. Limited by the retrospective nature of the design, our aim was to assess the potential benefits of integrating a patient-centered approach in delivering hypertensive care in accordance to quality indicators and practice guidelines.

\section{Conclusion}

There is room for improvement in adherence to clinical practice guidelines for treatment of hypertension. Task 
shifting, use of standing orders or technology to support many aspects at the clinic would improve compliance to guidelines. Adopting a patient-centered approach, through concepts of PCM, in delivering healthcare services could also improve the quality of care for hypertensive patients in Thailand.

\section{Supplementary information}

Supplementary information accompanies this paper at https://doi.org/10. 1186/s12875-020-01183-0.

Additional file 1: Table S1. The demographic data of two primary outpatient department clinics, FM clinic and SS clinic, in 1 year. The duration was 260 days.

Additional file 2: Table S2. The details of the checklist according to the 2015 Thai Hypertension Guidelines.

\section{Abbreviations}

BMl: body mass index; BP: blood pressure; Cr: creatinine; CPG: clinical practice guidelines; CV: cardiovascular; FM: family medicine; GFR: glomerular filtration rate; HDL-C: high-density lipoprotein cholesterol; LDL-C: Iow-density lipoprotein cholesterol; PCM: patient-centered medicine; PR: pulse rate; TC: total cholesterol; TOD: target organ damage; WC: waist circumference

\section{Acknowledgements}

Not applicable.

\section{Authors' contributions}

$N B, K P, W J, N D$, and CA were involved in the conception of the manuscript and the design. NB and PS collected the data. NB, KP, WJ, CP, and CA analyzed and interpreted the data. NB, KP and CA drafted the manuscript. All authors revised, read and then approved the final manuscript.

\section{Funding}

This study did not receive any specific grant from funding agencies in the public or not-for-profit sectors.

\section{Availability of data and materials}

Data set are available from the corresponding author on request.

\section{Ethics approval and consent to participate}

This study was a retrospective audit of routine clinical records. The study protocol was approved and written informed consent was waived by the Chiang Mai University Ethics Committee (No. 432/2560).

\section{Consent for publication}

Not applicable.

\section{Competing interests}

The authors have declared no competing interests.

\section{Author details}

${ }^{1}$ Department of Family Medicine, Faculty of Medicine, Chiang Mai University, 110 Inthawarorot Rd., Sriphum, Muang, Chiang Mai 50200, Thailand. ${ }^{2}$ Department of Biochemistry, Faculty of Medicine, Chiang Mai University, 110 Inthawarorot Rd., Sriphum, Muang, Chiang Mai 50200, Thailand.

Received: 7 January 2020 Accepted: 4 June 2020

Published online: 12 June 2020

\section{References}

1. Global Health Observatory $(\mathrm{GHO})$ data, Raised blood pressure, Situation and trends 2017 [cited World Health Organization. Available from: http://www. who.int/gho/ncd/risk_factors/blood_pressure_prevalence_text/en/.

2. Mills KT, Bundy JD, Kelly TN, Reed JE, Kearney PM, Reynolds K, et al. Global disparities of hypertension prevalence and control: A systematic analysis of population-based studies from 90 countries. Circulation. 2016;134(6):441.
3. Bittner DO, Klinghammer L, Marwan M, Schmid J, Layritz C, Hoffmann U, et al. Influence of cardiovascular risk factors on the prevalence of coronary atherosclerosis in patients with angiographically normal coronary arteries. Acad Radiol. 2017:24(5):580-6.

4. Phrommintikul A, Krittayaphong R, Wongcharoen W, Yamwong S, Boonyaratavej S, Kunjara-Na-Ayudhya $\mathrm{R}$, et al. Management of atherosclerosis risk factors for patients at high cardiovascular risk in realworld practice: a multicentre study. Singap Med J. 2017;58(9):535-42.

5. Chan SC, Chandramani T, Chen TY, Chong KN, Harbaksh S, Lee TW, et al. Audit of hypertension in general practice. Med J Malays. 2005;60(4):475-82.

6. Hiremath JS, Katekhaye VM, Chamle VS, Jain RM, Bhargava Al. Current practice of hypertension in India: focus on blood pressure goals. J Clin Diagn Res. 2016;10(12):25-8.

7. Mbui JM, Oluka MN, Guantai EM, Sinei KA, Achieng L, Baker A, et al. Prescription patterns and adequacy of blood pressure control among adult hypertensive patients in Kenya; findings and implications. Expert Rev Clin Pharmacol. 2017:10(11):1263-71.

8. Ahmad N, Hassan Y, Tangiisuran B, Meng OL, Abd Aziz N, Ahmad FU, et al. Guidelines adherence and hypertension control at a tertiary hospital in Malaysia. J Eval Clin Pract. 2013;19(5):798-804.

9. Ettehad D, Emdin CA, Kiran A, Anderson SG, Callender T, Emberson J, et al. Blood pressure lowering for prevention of cardiovascular disease and death: a systematic review and meta-analysis. Lancet (London, England). 2016; 387(10022):957-67.

10. Thai Hypertension Society. Thai Guidelines on The Treatment of Hypertension update 2015. 2015 [cited 2017 Sep 27]. Available from: http:// www.thaihypertension.org/files/GL\%20HT\%202015.pdf. Accessed 24 Sept 2017.

11. Barth JH, Misra S, Aakre KM, Langlois MR, Watine J, Twomey PJ, et al. Why are clinical practice guidelines not followed? Clin Chem Lab Med. 2016; 54(7):1133-9.

12. Robinson JH, Callister LC, Berry JA, Dearing KA. Patient-centered care and adherence: definitions and applications to improve outcomes. J Am Acad Nurse Pract. 2008:20(12):600-7.

13. American Diabetes Association. Standards of Medical Care in Diabetes-2017 Abridged for Primary Care Providers. Clin Diabetes. 2017:35(1):5-26.

14. Whelton PK, Carey RM, Aronow WS, Casey DE, Collins KJ, Dennison Himmelfarb C, et al. 2017 ACC/AHA/AAPA/ABC/ACPM/AGS/APhA/ASH/ ASPC/NMA/PCNA guideline for the prevention, detection, evaluation, and Management of High Blood Pressure in adults. A Report of the American College of Cardiology/American Heart Association Task Force on Clinical Practice Guidelines 2017:24430.

15. Stewart M, Brown JB, Weston WW, McWhinney IR, McWilliam CL, Freeman TR. Patient-centered medicine: transforming the clinical method. 2nd ed; 2003.

16. Ontario HQ. Continuity of care to optimize chronic disease management in the community setting: an evidence-based analysis. Ontario Health Technol Assessment Series. 2013;13(6):1-41.

17. Mahmoudian A, Zamani A, Tavakoli N, Farajzadegan Z, Fathollahi-Dehkordi F. Medication adherence in patients with hypertension: does satisfaction with doctor-patient relationship work? J Res Med Sci. 2017;22:48.

18. Bernheim SM, Ross JS, Krumholz HM, Bradley EH. Influence of patients' socioeconomic status on clinical management decisions: a qualitative study. Ann Fam Med. 2008:6(1):53-9.

19. Arpey NC, Gaglioti AH, Rosenbaum ME. How socioeconomic status affects patient perceptions of health care: A qualitative study. J Prim Care Community Health. 2017:8(3):169-75.

20. THE ROYAL COLLEGE OF FAMILY PHYSICIANS OF THAILAND. [cited 2017 Oct 19]. Available from: https://thaifammed.org/history/. Accessed 19 Oct 2017

21. Flynn SJ, Ameling JM, Hill-Briggs F, Wolff JLBL, Levine DM, Roter $D L$, et al. Facilitators and barriers to hypertension self-management in urban African Americans: perspectives of patients and family members. Patient Prefer Adherence. 2013;7:741-9.

22. Gottdiener JS, Reda DJ, Materson BJ, Massie BM, Notargiacomo A, Hamburger RJ, et al. Importance of obesity, race and age to the cardiac structural and functional effects of hypertension. The Department of Veterans Affairs Cooperative Study Group on antihypertensive agents. J Am Coll Cardiol. 1994;24(6):1492-8.

23. Colecraft EK, Asante M, Christian AK, Adu-Afarwuah S. Sociodemographic characteristics, dietary practices, and nutritional status of adults with 
hypertension in a semi-rural community in the Eastern region of Ghana. Int J Hypertens. 2018;2018:2815193.

24. Wu X, Li B, Lin WQ, Huang LL, Wang XX, Fu LY, et al. The association between obesity indices and hypertension: Which index is the most notable indicator of hypertension in different age groups stratified by sex? Clin Exp Hypertens. 2019;41(4):373-80.

25. Vathesatogkit P, Woodward M, Tanomsup S, Ratanachaiwong W, Vanavanan $S$, Yamwong $S$, et al. Cohort profile: the electricity generating authority of Thailand study. Int J Epidemiol. 2011:41(2):359-65.

26. Ridtidat R, Komanasin N. Mogkolwongroj P. Assessment of cardiovascular disease risk by the Rama-EGAT heart score in staff of Songkhla hospital. J Med Tech Phy Ther. 2015;27(1):14-27.

27. Supina P, Harncharoen K, Siri S, Maneesia A. Rama - EGAT heart score validity among acute coronary syndromes patients in Siriraj hospital. J Nurs Sci S1. 2009:27:77-82.

28. Clinical Practice Guideline on Pharmacologic Therapy of Dyslipidemia for Atherosclerotic Cardiovascular Disease Prevention. In: The Royal College of Physicians of Thailand, editor. 2016.

29. Matthys E, Remmen R, Bogaert PV. An overview of systematic reviews on the collaboration between physicians and nurses and the impact on patient outcomes: what can we learn in primary care? BMC Fam Pract. 2017;18(1):110.

30. Grissinger M. Guidelines for standard order sets. Pharmacy and Therapeutics. 2014;39(1):10-50.

31. Stewart M, Brown JB, Donner A, McWhinney IR, Oates J, Weston WW, et al. The impact of patient-centered care on outcomes. J Fam Pract. 2000;49(9): 796-804.

32. Lee King PA, Cederbaum JA, Kurzban S, Norton T, Palmer SC, Coyne JC. Role of patient treatment beliefs and provider characteristics in establishing patient-provider relationships. Fam Pract. 2015;32(2):224-31.

33. Adedapo AD, Akunne OO, Oladapo OO, Salako BL. Drug utilization and blood pressure control in ambulatory hypertensive patients: focus on those with compelling indications. Int I Clin Pharmacol Ther. 2017;55(3):237-45.

34. de Silva D. Helping measure person-centred care: A review of evidence about commonly used approaches and tools used to help measure personcentred care. London: The Health Foundation; 2014.

35. Ekman I, Wolf A, Olsson LE, Taft C, Dudas K, Schaufelberger M, et al. Effects of person-centred care in patients with chronic heart failure: the PCC-HF study. Eur Heart J. 2012;33(9):1112-9.

36. Cropley S. The relationship-based care model: evaluation of the impact on patient satisfaction, length of stay, and readmission rates. J Nurs Administration. 2012;42(6):333-9.

\section{Publisher's Note}

Springer Nature remains neutral with regard to jurisdictional claims in published maps and institutional affiliations.

Ready to submit your research? Choose BMC and benefit from:

- fast, convenient online submission

- thorough peer review by experienced researchers in your field

- rapid publication on acceptance

- support for research data, including large and complex data types

- gold Open Access which fosters wider collaboration and increased citations

- maximum visibility for your research: over $100 \mathrm{M}$ website views per year

At $\mathrm{BMC}$, research is always in progress.

Learn more biomedcentral.com/submissions 